\title{
A mandible of Diacodexis cf. gigasei (Artiodactyla, Diacodexeidae) from the Early Eocene locality of Palette (Bouches-du-Rhône, France)
}

\author{
Orliac Maëva ${ }^{1 *}$, Boivin Myriam¹, Tabuce Rodolphe ${ }^{1}$ \\ ${ }^{1}$ Institut des Sciences de l'Evolution de Montpellier, CC64 Université de Montpellier, Place Eugène Bataillon 34095, Montpellier cedex 5 France \\ *Corresponding author: maeva.orliac@umontpellier.fr
}

\begin{abstract}
This note presents the 3D model of the hemi-mandible UM-PAT 159 of the MP7 Diacodexis species D. cf. gigasei and 3D models corresponding to the restoration of the ascending ramus, broken on the original specimen, and to a restoration of a complete mandible based on the preserved left hemi-mandible.
\end{abstract}

Keywords: artiodactyl, Dentary, diacodexeid, MP7, Ypresian

Submitted:2018-05-07, published online:2018-07-03. https://doi.org/10.18563/journal.m3.60

\section{Model IDs \\ M3\#315 \\ M3\#316 \\ M3\#317}

\section{Description}

hemi-mandible virtually restored complete mandible virtually restored hemi-mandible before restoration

Table 1. List of models derived from the hemi-mandible of Diacodexis cf. gigasei UM-PAT 159 (ISEM, Montpellier)

\section{INTRODUCTION}

The specimen UM-PAT 159 retrieved from the MP 7 locality of Palette, Bouches-du-Rhône, France (Godinot et al., 1987), is a left hemimandible preserving p3-m3 and the alveoli of i1p2 (see Table 1). This specimen, referred to as Diacodexis cf. gigasei by Boivin et al. (in press), constitutes the most complete remain of European Diacodexis to date, and one of the best preserved mandible referred to Diacodexis. It preserves a large part of the ascending ramus, originally embedded in a marl matrix. Given the fragility of this specimen, including the particularly thin ascending ramus, we decided to restore it virtually. The CT Scan data and reconstruction of the virtual 3D model reveals that the shape of the ascending ramus of the mandible is strongly altered by fractures: its height and width are diminished by fractures and medial sliding of the bone (Fig. 1). The preserved part of the ascending ramus is broken in six principal fragments. Its virtual restoration allows describing this rarely preserved feature more accurately.

\section{METHODS}

The specimen UM-PAT 159 was scanned with a Skyscan/1076/ in-vivo micro CT scanner with an isotropic voxel size of 36 $\mu \mathrm{m}$. The mandible was virtually extracted from the sediment within a "labelfield" module of AVIZO 9.0 (Visualization Sciences Group), slice-by-slice manually with the limited range only option of the brush tool. A model presenting a restored version of the specimen has been produced by virtual restauration using ISE-MeshTools (Lebrun, 2014). The six broken parts of the mandibular branch have been segmented separately in different labelfields with AVIZO 9.0. The surfaces of the six resulting fragments have been extracted and their position before breakage was restored using ISE-MeshTools (Lebrun, 2014; Lebrun and Orliac, 2017). A single 3D object was created by merging together the seven surfaces. The mirror option allowed reconstructing the aspect of the complete mandible based on the restored 3D object. The 3D models, listed in Table 1, are provided in .ply format. Abbreviation: PAT, Palette; UM, Université de Montpellier.

\section{DESCRIPTION AND COMPARISON}

Despite of breakage, the coronoid process is complete and it could be restored in its entirety (Fig. 1). It is wide, slightly curved posteriorly, and shows a wide plateau at its dorsal extremity, and an anterior obtuse angle. Its anterior border is enlarged and lined laterally by a wide and shallow fossa for the masseter muscle. The mandibular condyle is partly preserved, separated from the ascending ramus by a wide and shallow incisura. The condyle, which was small in size, was situated well above the tooth row (estimated height based on restored specimen ca. $5 \mathrm{~mm}$ ). Still, the location of the condyle remains tentative and the space between the posterior base of the coronoid process and the condyle might be underestimated. The posterior-most part of the mandible is not preserved and the mandibular angle is completely missing. A reconstruction of the complete mandible was performed based on a mirror object of the left hemimandible and the preserved plane of the symphysis that provided the position of the 3D model of the right hemimandible generated with ISE-MeshTools (Fig. 1 E-F). Based on the restoration, the two condyles were situated ca. $2 \mathrm{~cm}$ apart. The restored aspect of the mandible highlights the facts that the anterior part of the snout of Diacodexis cf. gigase $i$ was elongated and narrow. Mandibles of Diacodexis figured in the literature are scarce and fragmentary. To our 

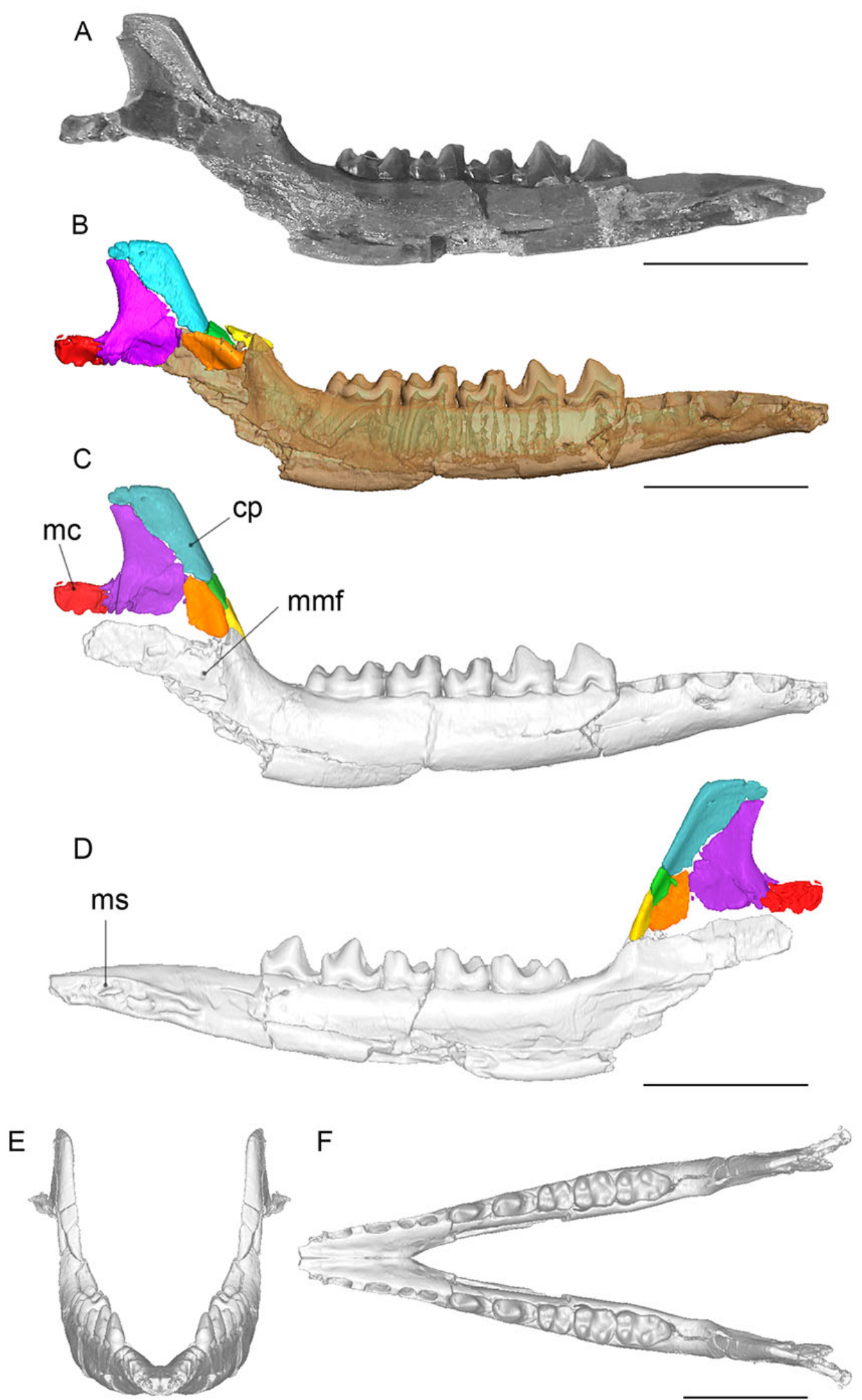

Figure 1. The left hemi-mandible of Diacodexis cf. gigasei PAT 159 from Palette, France. Lateral views illustrating: A) the physical specimen, B) volume rendering of the specimen generated by Avizo 9.0 once showing the six fragments of the ascending ramus in their original position, C) final restoration of the ascending ramus in lateral view, D) final restoration of the ascending ramus in medial view. E-F) reconstruction of the mandible based on the 3D model of the right hemimandible (PAT 159) in anterior (E) and occlusal (F) views. Scale bars $=1 \mathrm{~cm}$. Abbreviations: cp, coronoid process; mc, mandibular condyle; mmf, masseter muscle fossa; ms, mandibular symphysis. 


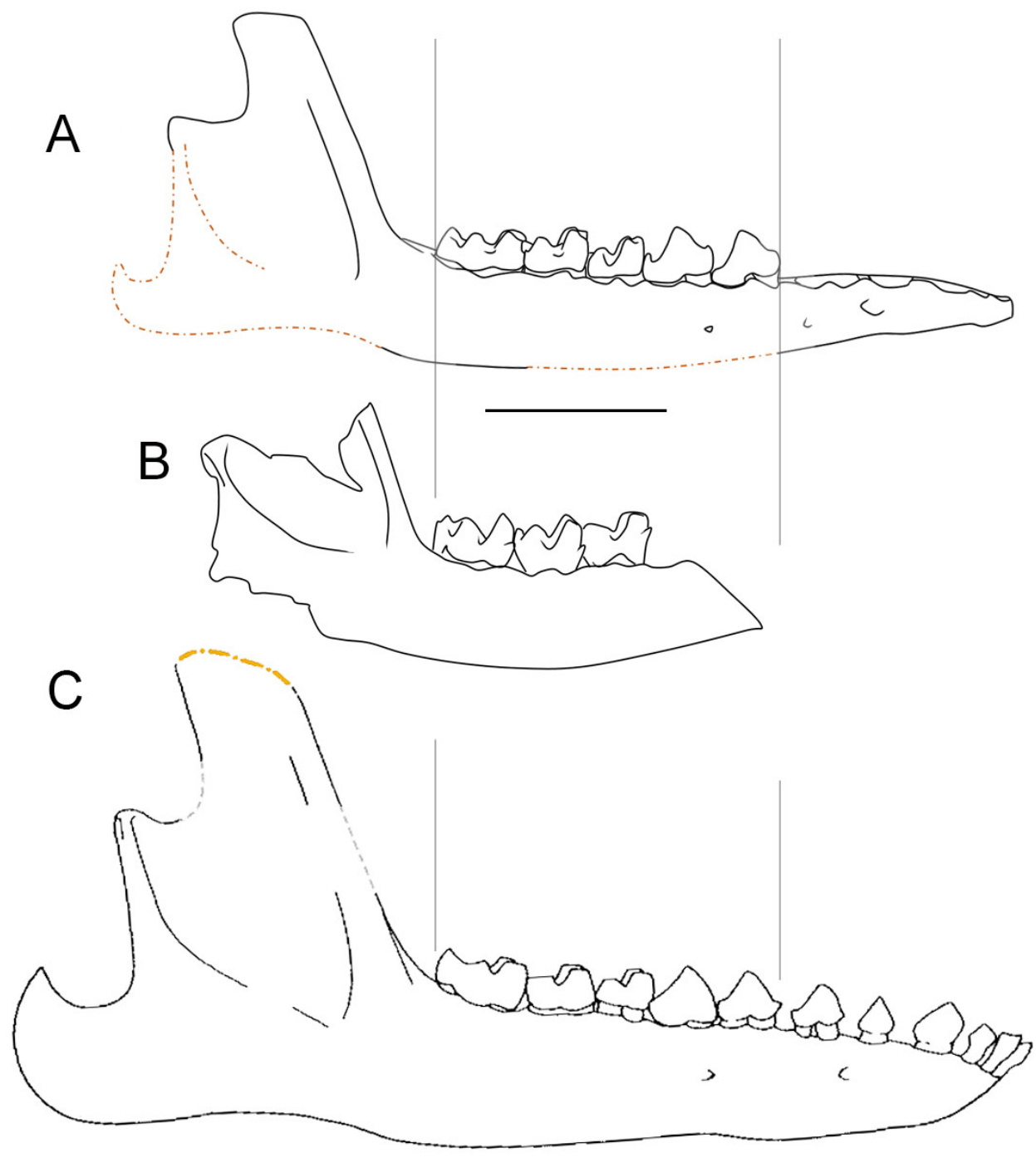

Figure 2. Comparison of the lateral views of the mandibles of A) Diacodexis cf. gigasei PAT 159 from Palette, France; B) Diacodexis indicus (GU 1622, mirror view, Kumar et al. 2010:fig. L), C) Diacodexis pakistanensis (modified after the composite reconstruction proposed by Russel et al. 1983:fig.1). Dotted lines indicate missing parts on A and C, grey dotted lines indicate hidden parts on the reconstruction of Russel et al. (1983). Scale bars $=1 \mathrm{~cm}$. 
knowledge, the most complete specimens are available for D. indicus (Kumar et al., 2010:fig. 5G,K), D. secans (Krishtalka and Stucky, 1985), and D. pakistanensis (Russell et al., 1983:fig.1; Thewissen et al., 1983). The morphology of the mandible was undescribed for European taxa before the description of the specimen PAT 159 from Palette by Boivin et al. (in press). The only other descriptions of an ascending ramus of Diacodexis were provided in the reconstruction illustrated by Russell et al. (1983:fig.1) for D. pakistanensis, and in the specimen GU 1622 published by Kumar et al. (2010:fig. I-L). D. gigasei, D. pakistanensis and D. indicus are very close morphologically as illustrated on Figure 2 . The coronoid process is more robust in D. pakistanensis, which is also the case for the body of the mandible. According to our virtual restoration, the condyle of the specimen from Palette was located higher above the tooth row than in $D$. indicus. However, the distance between the condyle and the anterior border of the ascending ramus perfectly matches between the two specimens, and the general good correspondence between our restoration and the proportions of the other Diacodexis mandibles figured in the literature supports the restored model proposed here.

\section{ACKNOWLEDGEMENTS}

3D data acquisitions were performed using the Micro-CT facilities of the MRI platform member of the national infrastructure France-BioImaging supported by the French National Research Agency (ANR-10-INBS-04, «Investments for the future»), and of the Labex CEMEB (ANR-10-LABX-0004) and NUMEV (ANR-10-LABX-0020).

\section{BIBLIOGRAPHY}

Boivin, M., Orliac, M. J, Antunes Telles, M., Godinot, M., Laurent, Y., Marandat, B., Vidalenc, D., Tabuce, R, in press. New material of Diacodexis (Mammalia, Artiodactyla) from the Early Eocene of Southern Europe. Geobios.

Godinot, M., Crochet, J. -Y., Hartenberger, J.-L., Lange-Badré, B., Russell, D.E., Sigé, B., 1987. Nouvelles données sur les mammifères de Palette (Eocène inférieur, Provence). In: Schmidt-Kittler, N. (Ed.), International Symposium on Mammalian Biostratigraphy and Paleoecology of the European Paleogene. Verlag Friedrich Pfeil, p. 273-288.

Krishtalka, L., Stucky, R.K., 1985. Revision of the Wind river Faunas, Early Eocene of central Wyoming, revision of Diacodexis (mammalia, artiodactyla). Ann.als of the Carnegie Museum 54, 413-486.

Kumar, K., Rose, K.D., Rana, R.S., Singh, L., Smith, T., Sahni, A., 2010. Early Eocene artiodactyls (Mammalia) from western India. Journal of Vertebrate Paleontology, 30(4), 1245-1274. https://doi.org/10.1080/02724634.2010.483605

Lebrun, R. ISE-MeshTools, a 3D interactive fossil reconstruction freeware. 12th Annual Meeting of EAVP, Torino, Italy; $06 / 2014$.
Lebrun, R., Orliac, M. J., 2017. MorphoMuseuM: an online platforme for publication and storage of virtual specimens. The Paleontological Society Papers 22, 183-195. https://doi. org/10.1017/scs.2017.14

Russell, D.E., Thewissen, J.G.M., Sigogneau-Russel, D., 1983. A new dichobunoid artiodactyl (Mammalia) from the Eocene of North-West Pakistan - II Cranial osteology. Proceedings of the Koninklijke Nederlandse Akademie van Wetenschappen, Series B, 3, 285-300.

Thewissen, J.G.M., Russell, D.E., Gingerich, P.D., Hussain, S.T., 1983. A new dichobunid artiodactyl (Mammalia) from the Eocene of north-west Pakistan. Proceedings of the Koninklijke Nederlandse Akademie van Wetenschappen, Series B, 86(2), 153-180. 